\title{
THE YOUTH LABOR MARKET IN THE 80s: DETERMINANTS OF RE-EMPLOYMENT \\ PROBABILITIES FOR \\ YOUNG MEN AND WOMEN
}

Lisa M. Lynch

Working Paper No. 2021

\author{
NATIONAL BUREAU OF ECONOMIC RESEARCH \\ 1050 Massachusetts Avenue \\ Cambridge, MA 02138 \\ September 1986
}

I would like to thank the participants of seminars at M.I.T. and Brandeis University, and my collegues at the National Longitudinal Survey for useful comments on previous drafts. This paper is a revised version of a report prepared under contract with the Employment and Training Division, U.S. Department of Labor. Any viewpoints presented in this paper do not necessarily represent the official position and policy of the U.S. Department of Labor. The research reported here is part of the NBER's research program in Labor Studies. Any opinions expressed are those of the author and not those of the National Bureau of Economic Research. 
NBER Working Paper \#2021

September 1986

The Youth Labor Market in the 80s:

Determinants of Re-Employment Probabilities for Young Men and Women

\section{ABSTRACT}

This paper presents an analysis of the determinants of re-employment probabilities for young workers in the U.S. Using data from the new National Longitudinal survey youth cohort a model is developed to analyze the transition probabilities from nonemployment to employment. The key factors examined include personal characteristics, unemployment income, local demand conditions, and duration dependence. There are significant differences between the labor market experiences of whites and nonwhites, and males and females. High school dropouts have many more difficulties in the labor market than those who remain in school longer and/or receive other types of training. Local demand conditions are a strong determinant of the duration of spells of nonemployment and there appears to be strong evidence of negative duration dependence in re-employment probabilities for both young males and young females.

Lisa M. Lynch

Sloan School of Management 50 Memorial Drive, E52-563.

Cambridge, MA

02139

(617) 253-0803 
Youth unemployment in the United States, as in most other developed countries, continues to be a challenging issue for policy-makers. For instance, figures from the Bureau of Labor statistics found the overall unemployment rate in the U.S. in the fourth quarter of 1982 to be 10.7 percent. However, for young workers, age 16-19, the unemployment rate was 24.3 percent, compared with 16.2 percent in 1972 . For black youths the numbers were even bleaker, with 49 percent of black youths unemployed in 1982 compared with 33 percent in 1972. If one includes the number of young workers who were out of the labor force but not in school or in the military these percentages become much greater.

Some argue that policy-makers should not be particularly concerned about youth unemployment because it is simply part of a productive and efficient job search process. In other words, time spent unemployed for young people is time spent accumulating valuable information about the labor market. However, periods of unemployment (or nonemployment) may have long term employment consequences for two major reasons. First, the loss of valuable work experience may make it more difficult for youths to find employment. Labor theories such as human capital imply that since substantial investment in human capital should occur in the early years of work, early joblessness is particularly costly. If there is no investment in human capital during periods of nonemployment the entire earnings profile of the worker will be depressed.

Perhaps more importantly, dual labor market theory suggests that early nonemployment might lead to poor work habits, weak labor force attachment, and general alienation from society. The joblessness experience itself may alter the attitudes of unemployed youths if they become more 
discouraged about their chances of successfully finding work and this spills over into their job search behavior. In addition, employers may use employment records as a signal of potential productivity. In this context even a one time shock which causes an increase in the level of unemployment may have long term consequences on the equilibrium level of unemployment.

The youth labor market experience can be analyzed in a variety of ways. One approach is to try to explain changes in youth unemployment using time series data. Studies using these type of data by Feldstein (1973), wachter and Kim (1982) and Clark and summers (1982) have attempted to show how aggregate demand, relative wages, and demographic changes have affected both cyclical and secular trends in youth unemployment. One of the advantages of time series analysis is that it is possible to assess the impact on aggregate youth unemployment of those explanatory variables that government policies might have some impact upon.

Using survey data, both cross sectional and longitudinal, it is possible to explore a variety of issues that can not be properly addressed with time series data. For example, studies by Meyer and Wise (1982), Rees and Gray (1982), Leighton and Mincer (1982), amd Clark and Summers (1982), have investigated how factors such as educational qualifications, family characteristics, turnover rates, employment histories, race and sex affect the probability of being unemployed for young workers in the U.S. These studies typically used data from the late 60's or mid 70's for their analyses.

Besides analyzing the characteristics of the stock of unemployed young people, several studies have attempted to determine the factors influencing the duration of unemployment. Studies by Ellwood (1982), 
using data from the National Longitudinal Survey, NLS, young men's cohort, and Corcoran (1982), using the NLS young women's cohort, have attempted to investigate the "scarring effects" of lack of work experience in the years immediately following school leaving in the late 60's and early 70's. Both papers find some evidence that after controlling for individual differences, early unemployment results in worse future employment and earnings prospects.

Moreover, the contributions of Stephenson (1976) and (1982), Heckman and Borjas (1980), Flinn and Heckman (1982a) and (1982b), Lynch (1985). and Wolpin (1984), have tried to link theoretical developments of search theory with data on either the duration of nonemployment or unemployment of young people. The studies by Stephenson, Heckman and Borjas, and Flinn and Heckman analyzed data from the early years of the NLs young men's and women's cohorts; thus their examinations of the youth labor market focused on a period of relative economic prosperity. Utilizing data from the new NLS youth cohort allows us to examine how the recession of the early 1980 's affected young workers and whether or not the importance of certain parameters of interest has changed over time. In particular, we shall investigate whether or not there is evidence of state dependency in youth nonemployment, the role of personal characteristics, unemployment income, and local demand conditions in explaining the determinants of re-employment probabilities for young workers.

There are five major findings in this paper:

(1) There are significant differences in the labor market experience of nonwhite compared to white youths and between males and females. The expected completed duration of a spell of nonemployment for a "typical" youth is slightly longer for males than for females. This expected 
duration of nonemployment is twice as long for nonwhite males and five times greater for nonwhite females.

(2) Completed years of schooling and non-governmental training significantly increase the probability of becoming re-employed.

(3) Young males who are not working have fewer chances of successfully transiting to employment as they get older. In other words, the male youth employment problem does not appear to go away as young males age.

(4) Local demand conditions are a strong determinant of the duration of spelis of nonemployment.

(5) There appears to be strong evidence of negative duration dependence in re-employment probabilities for both young males and young females.

The theoretical model used here is briefly described in the next section, followed in section two by a description of the data. In section three we present our results and in section four we discuss the problems associated with unobserved heterogeneity. Finally, in section five we summarize our major findings and discuss possible policy implications.

\section{The Model}

The theoretical framework we use for the following analysis is a simple job search model such as that presented by Mortenson (1970) and Lippman and McCall (1976). This model assumes that when a worker becomes unemployed, the expected completed duration of his or her unemployment or nonemployment spell (or inversely, the re-employment probability) will depend upon two probabilities -- the probability of receiving a job offer and the probability of then accepting the job offer. The probability of 
receiving a job offer will be determined by personal characteristics such as education and training and local demand conditions which are typically proxied by the local unemployment rate. The probability that an unemployed individual will then actually accept a job offer will be determined by their "reservation" wage. This is the minimal acceptable wage which equates the marginal benefits of accepting a job offer with the marginal costs of rejecting that offer and continuing to search. An individual will reject all offers below this wage. Factors which will determine this wage include variables such as the expected distribution of wages, the costs of search, any unemployment income, and the probability of receiving a job offer. The lower an individual's qualifications the lower will be the potential wages available and consequently the reservation wage will be lower. Higher unemployment income will not alter the probability of receiving a job offer but it will raise the reservation wage since the loss of earnings due to unemployment becomes smaller. Finally, a low probability of receiving a job offer will reduce the reservation wage since an unemployed individual knows that if she or he rejects a job it may be a long time before another offer is obtained.

The re-employment probability, $h(t)$, which is a function of the variables described above, is also known as the hazard or failure rate in renewal theory [1]. The hazard rate or re-employment probability can be expressed in the following form:

$$
h(t) d t=g(t) d t /(1-G(t))
$$

where $g(t) d t$ is the probability of accepting a job offer between time $t$ and $t+d t,(1-G(t))$ is the probability of not being employed at $t$ ime $t$, 
and $t$ is the duration of the current spell of nonemployment.

If we integrate eq. (1) we obtain the survivor function:

$$
1-G(t)=\exp \left[-\int_{0}^{t} h(z) d z\right]
$$

which implies the density function:

$$
g(t)=h(t) \exp \left[-\int_{0}^{t} h(z) d z\right]
$$

Although we are using search theory to justify the inclusion of particular variables in our estimation, we are not estimating a structural model but instead a reduced form search model. This means that we will observe the total effect of variables on the duration of nonemployment rather than the separate effects on the reservation wage and the probability of receiving a job offer. Since this type of estimation does not give us any direct insight into the role of reservation wages, our estimation cannot be viewed as a direct test of search theory. Our estimation does have the advantage of not making any specific distributional assumptions required in structural analyses. We are reluctant to impose any additional assumptions than are already necessary to study re-employment probabilities.

It is possible to use equations (2) and (3) to develop an appropriate likelihood for our data which will allow us to estimate the determinants of re-employment probabilities for young workers. We use two types of data for our study. The first data set is composed of the stock of young workers in the NLS youth cohort not working at the 1982 interview date. We can then update their labor history on a weekly basis through the 1983 interview and observe whether or not they have been successful in finding 
employment during that interval. If they are successful, we can identify the exact date of their re-employment. This implies that our likelihood will contain observations on both completed and uncompleted spells of nonemployment. The appropriate form for the likelihood given this type of data is:

$$
L=\prod_{i=1}^{N U}\left[\frac{1-G_{i}\left(t_{i}+h_{i}\right)}{1-G_{i}\left(t_{i}\right)}\right] \prod_{j=1}^{N E}\left[\frac{g j(t j+s j)}{1-G_{j}(t j)}\right]
$$

where $\mathrm{NU}$ is the number of individuals still not working by the second interview, $t$ is the duration of joblessness at the first interview, $h$ is the number of weeks between the two interviews, NE is the number of individuals who find a job by the second interview, and $s$ is the exact number of weeks after the first interview before becoming re-employed. This form of the likelihood allows us to control for the length bias problems associated with stock data.

We also examine a smaller subsample which is composed of the inflow into nonemployment at the 1982 interview date. Therefore, only those individuals who are just entering the state of nonemployment from employment are included in this group. The likelihood for this smaller inflow sample is:

$$
\left.L=\prod_{i=1}^{N U}\left[1-G_{1}\left(t_{i}+h_{i}\right)\right]\right]_{j=1}^{N E}\left[g_{j}\left(t_{j}+s_{j}\right)\right]
$$

In order to operationalize this likelihood we need to select an appropriate functional form for G. Since we have censored observations (uncompleted spells of nonemployment by the second interview) we have chosen two distributions, the Weibull and the Log-logistic, which are convenient for censored data. We assume that the hazard or re-employment probability can be decomposed as follows: 
$h(t)=\psi_{1}(X) \psi_{2}(t)$

where we assume for both distributions that:

$$
\psi_{1}(\mathrm{X})=\exp \left[\mathrm{X}^{\prime} \mathrm{B}\right]
$$

$\mathrm{X}^{\prime}$ is a vector of personal characteristics and local demand conditions. For the Weibull distribution the survivor function, $1-G(t)$ is:

$$
1-G(t)=\exp \left(-\exp \left(X^{\prime} B\right) t^{\alpha}\right)
$$

and for the Log-logistic distribution the survivor function is:

$$
1-G(t)=\left(1+t^{\alpha} \exp \left(X^{\prime} B\right)\right)^{-1}
$$

Therefore, the hazard functions for the weibull and the Log-logistic distributions are respectively:

$$
\begin{aligned}
& h(t)=\alpha t^{(\alpha-1)} \exp \left(X^{\prime} B\right) \\
& h(t)=\alpha t^{(\alpha-1)} \exp \left(X^{\prime} B\right)\left(1+t^{\alpha} \exp \left(X^{\prime} B\right)\right)^{-1}
\end{aligned}
$$

The Weibull hazard is monotone decreasing if $\alpha<1$, monotone increasing if $\alpha>1$, and constant if $\alpha=1$ (this is also the exponential hazard). In other words, if the hazard is constant then differences in duration spells will only be determined by personal characteristics, local demand conditions and other determinants of the reservation wage and the probability of receiving a job offer. If the hazard is decreasing (increasing) then, ceteris paribus, the subsequent expected duration of a 
spell of nonemployment will be larger(smaller) the longer the individual is not working. Job search theory predicts that as the spell of unemployment lengthens the reservation wage will fall, implying an increasing hazara (positive duration dependence). On the other hand, if employers use employment records as a signal of potential productivity then the hazard will be decreasing (negative duration dependence). The hazard may also decline if the experience of not being employed causes greater discouragement amongst those youths who experience longer periods of nonemployment.

The Log-logistic hazard is identical to the Weibull hazard apart from the term appearing in the denominator. It is monotone decreasing if $\alpha \leq 1$ and if $\alpha>1$ it resembles the log-normal hazard in that it increases to a single maximum and then decreases towards zero thereafter. This formulation allows us to see whether or not there may actually be a period of positive duration dependence followed by negative duration dependence.

\section{The Data}

For our analysis we have chosen to examine the determinants of the duration of periods of nonemployment for youths in the National Longitudinal survey, NLS, youth cohort. The NLS youth cohort is a sample of 12,686 males and females who were 14 to 21 years of age at the end of 1978. They were first interviewed in 1979 and have been interviewed every year since about their education, jobs, military service, training programs, marriage, health, and attitudes. The response rate in 1985 was over 95 percent of the group originally interviewed. We have restricted our sample to those youths who were not employed at the 1982 interview but were not in school or in the military. In addition, we have required 
that the individual's date of last enrollment in school was before the starting date of their last job and that they did not return to school in the year following the 1982 interview. All of the youths in our sample have been employed immediately before their current spell of joblessness. We chose this selection criteria so that we would restrict our analysis to the experience of young workers who appear to have entered the labor market "permanently". We did not wish to model the transition from school to first job or to include in our study those youths who only entered the labor market during the summer between school sessions. Using the 1983 interview we were able to determine whether or not youths not working at the 1982 interview obtained a job during the following year. For those who were successful in finding employment we know the completed spell length of their period of nonemployment. For those still not working by the 1983 interview, we observed an "uncompleted" spell length. Approximately eighty percent of the males and sixty-three percent of the females have completed their spell of nonemployment by the 1983 interview. We concentrated initially on transitions from nonemployment to employment because of the difficulty with the NLS data of identifying the exact sequence of weeks spent unemployed or out of the labor force. There is evidence, however, (Gonul (1985)) for youths and in particular for young males, that there is little difference between weeks spent "unemployed" and "out of the labor force."

Table 1 presents some selected unweighted characteristics of the sample we have examined. The weighted characteristics are almost identical with the exception of nonwhites. The NLs has deliberatly over-sampled nonwhites so that while nonwhites represent 348 of our total sample they are only $20 \%$ of the weighted sample. There are some major 
differences between the males and females in our sample. Perhaps the most striking difference is the much higher percentage of females who are married and not living at home. Males are more likely to be on layoff than females and to have earned on average higher wages in their last job. Females are earning hourly wages very close to the minimum wage while the average hourly wage for males is over $\$ 4.00$. Given these differences between males and females we have analyzed these two groups separately.

It is sometimes argued that the U.S. youth. labor market is characterized by the majority of young people going in and out of work quite frequently and experiencing relatively short spells of joblessness. However, as the frequency distribution presented in Table 2 indicates, this is probably not an accurate description of the labor market experience of all of our sample. In Table 2 only eighteen percent of the males and fourteen percent of the females have spells of nonemployment less than three months. Over a third of the males and over fifty-five percent of the females have spells of nonemployment greater than fifty-two weeks.

Our theoretical model implies that the re-employment probability, $h(t)$, is determined by the probability of receiving a job offer and the probability of then accepting that job offer. Given the distribution of wages, the factors which will be the most likely to influence the probability of receiving a job offer are local demand conditions (proxied here by the local unemployment rate) and personal characteristics. We expect that nonwhites might experience longer durations of joblessness, especially if they are being discriminated against in the labor market. Other variables which might determine the probability of receiving a job offer include human capital variables such as whether or not the 
individual had any training (vocational, technical, other skills, or governmental training programs) and the completed number of years of schooling. If an individual is on temporary lay-off, we would also expect that their duration of nonemployment would be shorter. Other variables we have used include whether or not the individual lives in an SMSA (the "inner city" problem), whether or not they are healthy, whether or not they live at home (a proxy for search intensity or parental pressure to get a job), age, whether or not they are married, and the length of the last spell of nonemployment.

All of the above variables may also affect the reservation wage. A variable which is assumed to have a direct affect upon the reservation wage but not on the probability of receiving a job offer is unemployment income. Unemployment income subsidizes job search so that the more unemployment income an individual receives the higher the reservation wage, ceteris paribus. In our analysis we use the average amount of unemployment compensation the respondent receives while unemployed. As shown in Table 1 many of the respondents do not receive unemployment compensation primarily because they are not eligible for it but also because they often do not claim it even when eligible.

In previous studies researchers have included the ratio of unemployment income to expected earnings. This "replacement ratio" has no specific justification within a job search framework so we include the two variables separately in our estimation. To proxy for expected earnings we use a predicted earnings variable obtained from an earnings equation estimated for all employed youths in the cohort at the 1983 interview. As Nickell (1979) has noted, it is more appropriate to use a fitted value from an earnings equation than any actual level of income, which will be endogenous. However, there are still problems of 
endogeneity even with this measure so we also present results of a true reduced form model where we do not include expected earnings. [2].

\section{The Results}

Tables 3 and 4 present our findings [3] on the determinants of re-employment probabilities for young males and females. Equation 1 estimates the Weibull hazard without any explanatory variables to establish "starting" values for alpha and the log likelihood. Alpha indicates not only whether or not the hazard is increasing, decreasing, or constant but it is also a measure of misspecification since it can be shown that the inclusion of significant variables will raise the value of alpha. Equations 1, 2, and 3 assume a Weibull distribution for the hazard while equation 4 assumes the Log-logistic distribution. This allows us to examine the sensitivity of the parameter estimates to the somewhat arbitrary distributional assumptions which we have made.

Personal characteristics which lower the re-employment probability for both males and females include being nonwhite, having completed fewer years of school, and poor health. For females, being married decreases their re-employment probability, while receiving some form of vocational or technical training, or being on layoff, significantly raises their re-employment probability. It is interesting to observe the positive effects of training for females and none for males even though Table 1 shows that the average amount of technical, vocational and other skills training is about the same across the two groups.

Another personal characteristic that is important for males is age. Usually when discussing how to solve the problem of young workers there is the easy "solution" of just waiting for them to get older. However, for young males in our sample their re-employment probability actually 
declines as they age. This is similar to findings presented in Ballen and Freeman (1983).

Local demand conditions seem to be critical for both males and females regardless of distributional assumptions. This implies that these youths are not simply sampling a variety of jobs and experiencing short spells of joblessness between "samples". They appear to be constrained by the probability of receiving a job offer. This is also consistent with Holzer's (1986) findings (using data from the 1981 NLS youth cohort survey) that very few of those who are unemployed turn down job offers.

We find in all of our equations that neither the expected wage or unemployment income are significantly different from zero. Given the small percentage of our sample that actually receives any form of unemployment income this result is perhaps not so unexpected.

In all of the equations presented we can not reject the hypothesis that the hazard is declining and it is declining even faster for the females than for the males. In the Log-logistic model for males, alpha equals 1.06 suggesting that the hazard first increases and then decreases. However, given the standard error we are not able to reject the hypothesis that alpha equals one and in the Log-logistic case this implies a declining hazard. This suggests that for both males and females the probability of becoming re-employed, ceteris paribus declines with the duration of a spell of nonemployment, contrary to what our simple job search model would predict.

We repeated our analysis on a more homogeneous subsample of youths composed of those with only twelve years or less of completed schooling. These results are presented in Appendix A. The results are virtually identical to what we found for the larger sample except that we also 
observed evidence of lagged duration dependence. For this group of youths not only does the present duration of their spell of nonemployment decrease their re-employment probability but also the length of their most recent past spell of joblessness (always excluding time spent in school). This subsample typically has been in the labor force for a longer period of time than our original sample.

In an attempt to see how sensitive our parameter estimates are to the distributional assumptions we made about the hazards, we estimated both Weibull and Log-logistic hazards. While most of the coefficients are virtually identical (after dividing them by the value of alpha) this is not the case for the layoff coefficient in the male and female equations and the SMSA coefficient in the male equation. Being on layoff dramatically raises the probability of becoming re-employed in the Log-logistic specification compared with the Weibull specification for both males and females.

Since the coefficients presented in Tables 3 and 4 are not particularly intuitive we calculated the expected completed duration of a spell of nonemployment for different types of individuals using the coefficients from equations 3 in Tables 3 and 4 . Integrating the Weibull survivor function, equation 8 , we obtained the expression for the expected completed duration of a spell of nonemployment:

$$
E(T)=\Gamma(1 / \alpha+1) \exp \left(-\left(X^{\prime} B\right) / \alpha\right)
$$

A "typical" male is white, is 21 years old in 1982, has completed 11 years of school, is unmarried, lives in an SMSA with an 11 percent unemployment rate, is healthy, lives at home with his parents, has no formal job training, is not on layoff, and has had a past spell of 
nonemployment of 15 weeks. The expected completed duration of joblessness for this typical male is 7.2 weeks. If we make this male nonwhite his expected spell length increases to 14.1 weeks. If instead he 1 ives in an SMSA with a 20 percent unemployment rate his spelI increases from 7.2 weeks to 19 weeks. Finally, if this male is "typical" but he has finished college his expected completed duration is only 2.6 weeks.

If we repeat this exercise for females (the same characteristics as for males except that completed years of school equals 12 and the length of the past spell of nonemployment equals 18 weeks) we find that the expected completed duration of joblessness for a typical female is only 5.4 weeks. However, if we make this female nonwhite her spell length increases dramatically to 24 weeks. If instead she lives in an SMSA with a 20 percent unemployment rate her spell length increases from 5.4 weeks to 17.8 weeks. If she has completed college her expected spell is only 1.2 weeks or if she has taken some sort of vocational, technical or other skills training her expected spell length is only 2.6 weeks. Finally, if she has all of the "typical" characteristics except that she is married and is not living at home with her parents her expected completed duration of nonemployment increases to 20.3 weeks. This last finding highlights an important difference between the males and females in our sample. Even though these individuals are relatively young there is already some evidence that non-labor market activities of young females alters their labor market experience from that of males.

To see how the current length of nonemployment affects the probability of becoming re-employed we can see how the re-employment probability, equation 10, declines for a "typical" respondent with the number of weeks nonemployed. The re-employment probability for either a 
"typical" male or female who has not been working for one week is slightly greater than 30 percent. If they have not been working for eight weeks this drops to 8 percent and if they have not been employed for fifty two weeks their re-employment probability is only 2 percent.

\section{Unobserved Heterogeneity}

Before concluding that there is negative duration dependence in the transition probability from nonemployment to employment we must discuss the possibility that our parameter estimates may be biased due to the omission of unobserved variables such as motivation. As is well known this may lead to spurious negative duration dependence. Equation 1 in Tables 3 and 4 presents estimates of alpha excluding all the explanatory variables for males and females. Including a wide range of observable factors increases the estimate of alpha from .32 to .37 for the males and from .2 to .3 for the females. It is hard to imagine how any unobserved heterogeneity that remains in our sample will have an effect large enough on alpha to raise it significantly over one given that including a wide range of significant observable variables does not alter its value very much. Nevertheless in this section we present some adaitional attempts to take into account the impact of unobserved heterogeneity on our parameter estinates.

As discussed in Cox and Oakes (1984) misspecification of the baseline distribution of the hazard may or may not have a significant effect on the estimates of the coefficients of the explanatory variables. However the standard errors on these coefficients will be too low(high) if the dispersion of the baseline distribution is more(less) than that specified. Therefore we estimated Cox's (1972) proportional hazard model. This model is nonparametric or semi-parametric in the sense that 
it involves an unspecified function in the form of an arbitrary base-line hazard function. This proportional hazards model is specified as:

$$
h(t ; X)=h_{u}(t) \exp \left(X^{\prime} B\right)
$$

where $h_{0}(t)$ is an arbitrary and unspecified base-line hazard function. The model is "distribution free" since the estimates of the B's depend only on the rank ordering of the dependent variable vector and are invariant with respect to monotonic transformations on the dependent variable. (See Kalbfleisch and Prentice (1980) and Cox and Oakes (1984) for a more detailed discussion). While using this method means that we will not be able to say anything about state dependency in youth nonemployment it ajoes allow us to examine the robustness of the estimates of other parameters of interest.

No intercept parameter is estinated for the proportional hazards model since the likelihood is invariant with respect to translations of any of the independent variables. The likelihood we use for this estimation allows us to have censored and tied data, however, it does not allow us to condition on length of nonemployment at the first interview date. Therefore, we restrict our analysis to a sample of youths who were just entering the state of joblessness from employment at the 1982 interview date. Our findings on this reduced sample are presented in Appendix B where we first estimate the Weibull hazard specifying the likelihood in the form of equation (5) and then estimate cox's proportional hazard with Breslow's (1974) modification for tied data. Comparing results in Tables 6 and 7 indicates that while the coefficients obtained using Cox's proportional hazard model are somewhat smaller than those obtained assuming a Weibull aistribution, they do not appear to be 
significantly different.

A major disadvantage of this method given the nature of our data is the substantially reduced sample size. Another approach is to follow the suggestions of Heckman and Singer (1984) and control for unobserved heterogeneity in a nonparametric way. Assume that we have a population divided into $J$ homogeneous groups. The hazard then for individual $i$ with measured covariates $\mathrm{X} i$ in group $j$ is:

$$
h_{i j}(t)=\alpha t^{(\alpha-1)} \exp \left(X_{i}^{\prime} B+\lambda_{j}\right)
$$

The survivor function associated with this hazard is:

$$
1-G(t)=\sum_{j=1}^{J} p_{j}\left[\exp \left(-\exp \left(x^{\prime} B+\lambda_{j}\right) t^{\alpha}\right]\right.
$$

and the density is:

$$
g(t)=\sum_{j=1}^{J} p_{j}\left[\alpha t^{(\alpha-1)} \exp \left(X^{\prime} B+\lambda_{j}\right)\left(\exp \left(-\exp \left(X^{\prime} B+\lambda_{j}\right) t^{\alpha}\right)\right]\right.
$$

The number of groups, $\mathrm{J}$, is unknown so we began with $\mathrm{J}=1$ and incremented until the likelihood failed to show a significant improvement. The results presented in Tables 3 and 4 are equivalent to the case of $J=1$. We then assumed the existence of two mass points $(J=2)$ and we estimated the appropriate likelihood function obtained by substituting equations 15 and 16 into equation 4. There was no significant improvement in the value of the likelihood and all of the parameter estimates were virtually identical to those obtained with $\mathrm{J}=1$ for both males and females. The estimate of $p$ was either at or near the upper or lower bound of $p$, and $\lambda_{1}$ and $\lambda_{2}$ were identical. [5] 
Unfortunately, even this approach does not guarantee that there is no problem of unobserved heterogeneity. As Trussell and Richards (1986) have shown, even with this type of nonparametric representation of heterogeneity, results can still be sensitive to the choice of the hazard. However, apart from creating a truly nonparametric estimator all we can do is try a variety of approaches and observe what happens to our estimates. In our case the fundamental finding is that the results presented in section 3 are quite robust even when the heterogeneity problem is accounted for. This probably reflects the relatively greater homogeneity of our sample compared with the composition of other samples where some of these approaches have been applied.

\section{v. Conclusions}

In the previous sections we have tried to identify significant factors which affect the length of joblessness for youths. We have grouped together time spent out of the labor force lout not in school or in military service) with time spent unemployed (and actively searching for employment on a weekly basis) and redefined this as nonemployment time. We have then attempted to determine the factors which will affect the probability of successfully becoming re-employed for young workers using data on their employment histories during the severe recessionary period of the early 1980's.

The re-employment probability for both young males and females in our sample is significantly reduced if the individual is nonwhite even after controlling for a wide range of other characteristics. In spite of affirmative action legislation nonwhites still seem to be experiencing much more difficulty than their white counterparts in the labor market. 
Our results may still underestimate the "true" racial diferences among young workers since we have conditioned our estimation on having been employed before becoming nonemployed. Ballen and Freeman (1983) show that many black youths never even find that first job.

Local demand conditions play an important role for both males and females. Being in a depressed area more than doubles the expected duration of nonemployment for males and more than triples the spell length for females. This suggests that youth unemployment should significantly decline as the economy improves.

Investments in human capital are important determinants of the probability of transiting from nonemployment to employment. There are high returns to having completed college for both the males and females. Unfortunately, in our sample, 40 percent of the females have not even completed high school with only 16 percent of them less than 19 years old. Fifty two percent of the males have not completed high school with only 18 percent of them under 19 years of age. There seems to be an increasing trend for youths in the U.S. not to complete high school which appears inconsistent with the demands of the new high tech growth areas of our econorny.

Training in the form of vocational, technical or other skills training significantly increases the re-employment probability of females. This variable does not seem to affect males even though the same percentage of males and fernales have had this type of training. Training obtained in some sort of government program does not seem to be very effective in improving the chances of these youths to become employed.

There appear to be significant differences in the labor market experience of male and female workers. There is evidence that the non 
labor market activities of females alters their labor market experience. In particular, as soon as females become married their nonemployment spells significantly lengthen. Even when employed there still appears to be substantial labor market segregation with only 15 percent of the females in our sample employed in manual work in their last job while over 57 percent of the males were manual workers in their last job. Perhaps as important as the variables that are significant are those that are not. In particular, unemployment compensation is never a significant explanatory variable in any of our equations. We would not expect, therefore, that cuts in unemployment compensation would be an effective tool to shorten the length of unemployment spelis for young workers.

Finally, there is strong evidence of negative duration dependence in re-employment probabilities of young workers. This implies that as the spell length of nonemployment increases the probability of becoming re-employed declines sharply for the youths in our sample. This may be the result of employer's using the length of a youth's spell of nonemployment as a signal of some undesirable but unobservable characteristic or youths becoming more discouraged as their spell length increases. This suggests that for many youths in the U.S. today their nonemployment experience is not part of a productive job search process where they are incurring short spells of joblessness in order to find better employment. 
FOOTNOTES

1.) See Cox (1962), Kalbfleisch and Prentice (1980), and Cox and Oakes
(1984).

2.) We tried both wage in last job and a predicted earnings variable but have found our estimates not sensitive to the choice of variable.

3.) The estimates presented here were obtained using a modified Newton algorithm from the National Algorithms Group Library, number E04LBF which required analyticaliy derived first and second derivatives. These derivatives were then checked with NAG routines E04HCF and E04HDF which give numerical approximations to the derivatives using
the objective function provided.

4.) It should be noted that the asymptotic normality of our estimates in Table 7 given this likelihood has not yet been formally proven. See cox and Oakes (1984).

5.) We used over ten different starting points for both the male and female equations and found that our results remained the same no matter where we started the search from. 


\section{REFERENCES}

Ballen, J. and Freeman, R. (1983). "Transitions between employment and nonemployment", NBER Conference on Inner City Black Youth

Unemployment.

Breslow, N. E. (1974). "Covariance analysis of censored survival data." Biometrics, vol. 30, pp. 89-99.

Clark, K. and Summers, L. (1982). "The dynamics of youth unemployment", in The Youth Labor Market Problem: Its nature, causes and consequences, edited by R. Freeman and D. Wise, University of Chicago Press.

Corcoran, M. (1982). "The employment and wage consequences of teenage women's nonemployment", in The Youth Labor Market Problem: Its nature, causes and consequences, edited by R. Freeman and D. Wise, University of Chicago Press.

Cox, D. R. (1962). Renewal Theory, London: Methuen.

Cox, D. R. (1972). "Regression models and life tables (with discussion)", Journal of the Royal Statistical Society, B series, vol 34, pp. 187220 .

Cox, D. R. and Oakes, D. (1984). Analysis of Survival Data, London: Chapman and Hall.

Ellwood, D. (1982). "Teenage unemployment: Permanent scars or temporary blemishes". in The Youth Labor Market Problem: Its nature, causes and consequences, edited by R. Freeman and D. Wise, University of Chicago Press.

Feldstein, M. (1973). Lowering the Permanent Rate of Unemployment, U.S. Congress Joint Economic Committee, Washington D.C.: GPO.

Flinn, C. J. and Heckman, J. J. (1982a). "Models for the analysis of labor force dynamics", in Advances in Econometrics, edited by Basmann and Rhodes, Greenwich: JAI Press, pp. 35-95.

Flinn, C. J. and Heckman, J.J. (1982b). "New methods for analyzing structural models of labor force dynamics", Journal of Econometrics, vol. 18, pp. 115-168.

Gonul, F. (1985). "A test on the equivalence of unemployment and out-ofthe labor force states in the absence of complete transition information", mimeo, OSU.

Holzer, H. (1986). "Search method use by unemployed youth", NBER discussion paper no. 1859.

Heckman, J. J. and Borjas, G. (1980). "Does unemployment cause future unemployment? Definitions, questions and answers from a continuous time model of heterogeneity and time dependence". Economica, vol. 47 . pp. 247-283. 
Heckman, J. J. and Singer, B. (1984). "A method for minimizing the impact of distributional assumptions in econometric models for duration data. Econometrica, vol. 52, pp. 271-320.

Kalbfleisch, J. D. and Prentice, R. C. (1980). The Statistical Analysis of Failure Time Data, New York: Wiley.

Lancaster, T. (1979). "Econometric models for the duration of unemployment," Econometrica, vol. 47, pp. 939-956.

Leighton, L. and Mincer, J.(1982). "Labor turnover and youth unemployment," in The Youth Labor Market Problem: Its nature, causes and consequences, edited by R. Freeman and D. Wise, University of Chicago Press.

Lippman, S. and McCall, J.J. (1976). "The economics of job search: A survey", Economic Inquiry, vol 14, pp. 155-189.

Lynch, L. M. (1985). "State dependency in youth unemployment: A lost generation?", Journal of Econometrics, vol. 28, pp. 71-84.

Meyer, R. and Wise, D. (1982). "High school preparation and early labor force experience", in The Youth Labor Market Problem: Its nature, causes and consequences, edited by R. Freeman and D. Wise, University of Chicago Press.

Mortenson, D.T. (1970). "Job search, the duration of unemployment and the Phillips curve", American Economic Review, pp. 847-862.

Nickell, S.J. (1979). "Estimating the probability of leaving unemployment" Econometrica, pp. 1249-1266.

Rees, A. and Gray, W. (1982). "Family effects in youth unemployment", in The Youth Labor Market Problem: Its nature, causes and consequences, edited by R. Freeman and D. Wise, University of Chicago Press.

Stephenson, S. (1976). "The economics of youth job search behavior", Review of Economics and Statistics, pp. 104-111.

Stephenson, S. (1982), "A turnover analysis of joblessness for young women," in Research in Labor Economics, vol. 5, pp. 279-318.

Trussell, J. and Richards, T. (1986). "Correcting for Unmeasured Heterogeneity in Hazard Models: An Application of the Heckman-Singer Strategy to Demographic Data." Sociological Methodology, pp. $242-276$.

Wachter, M. and Kim, C. (1982). "Time series changes in youth joblessness", in The Youth Labor Market Problem: Its nature, causes and consequences, edited by R. Freeman and D. Wise, University of Chicago Press.

Wolpin, K. (1984). "Estimating a structural search model: The transition from school to work", OSU working paper \#84-32. 
Table 1 Characteristics of Those Not Working at the 1982 Interview

$$
\text { Males }(\mathrm{N}=761) \quad \text { Females }(\mathrm{N}=892)
$$

Variable

AGE in 1982

SCHOOL (years)

LOCAL UNEMPLOYMENT RATE

WEEKLY PAY IN LAST JOB

PERCENTAGE RECEIVING

UNEMPLOYMENT COMP

NONWHITE

MARRIED

ILL HEALTH

LIVE AT HOME

TRAINING (all except gov)

TRAINING (government)

ON LAYOFF

LIVE IN SMSA

LENGTH OF LAST SPELL OF NONEMPLOYMENT
Mean or $q$ of Sample

20.6

11

10.78

$\$ 165.67$

$21 \%$

$36 \%$

$14 \%$

$5 \%$

$63 \%$

$28 \%$

$7 \%$

148

$70 \%$

15 weeks
Mean or $\because$ of Sample

20.8

11.5

$10.5 \%$

$\$ 135.64$

$10 \%$

$32 \%$

$41 \%$

$14 \%$

$38 \%$

$30 \%$

6\%

$5 \%$

$71 \%$

18 weeks 
Table 2 Frequency Distribution of the Number of Weeks of Completed and Uncompleted Spelis of Nonemployment by 1983 Interview

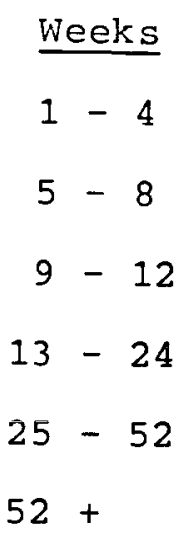

Weeks

$52+$
Males

$$
7.3 \%
$$

$6.1 \%$

$5.1 \%$

$15.7 \%$

32.68

$33.2 \%$
Females

$6.8 \%$

$3.8 \%$

$2.9 \%$

$11.0 \%$

23.88

$51.7 \%$ 
Table 3 Maximum likelihood estimates of re-employment probabilities (standard errors in parentheses)

$$
\text { Males }(\mathrm{N}=761)
$$

Variable

Eq. 1 (Weibul1)

CONSTANT

ALPHA *

NONWHITE

AGE

SCHOOL

MARRIED

LOG UB

LOG PAY

LOCAL URATE

HEALTHY

LIVE AT HOME

TRAINING VTS

TRAINING GOV

LAYOFF

SMSA

LAG DURATION DEPENDENCE

LOG LIKELIHOOD $=-2476.94$
0.02

$(0.04)$

Eq. 2 (Weibull)

$-1.10 * *$

$(0.04)$

$0.37 *$ *

$(0.05)$

$$
(0.32 * *
$$

$-$

$-$

$-$

$-$

$-$

$-$

$-$

$-$

$-$

$-$

$-$

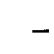

$-$

$-\quad-0.005$

$(0.003)$

$-2455.62$

0.25

$(0.44)$

$-0.04 * *$

$(0.01)$

0.46 **

$(0.21)$

0.16

$(0.10)$

$-0.11$

$(0.09)$

0.01

$(0.18)$

0.22

(0.13)

$-0.19$

$(0.11)$
Eq. 3

(Weibull)

$-0.10 * *$

$(0.04)$

0.37 * *

$(0.04)$

$-0.25 *$ *

$(0.09)$

$-0.03$

$(0.02)$

0.054 **

$(0.027)$

0.10

$(0.12)$

0.01

$(0.01)$

$-0.04 * *$

$(0.01)$

$0.46 * *$

$(0.21)$

0.16

$(0.10)$

$-0.11$

(0.09)

0.01

$(0.17)$

0.23

(0.13)

-0.17 *

$(0.09)$

$-0.005$

$(0.003)$

$-2455.74$
Eq. 4

(Log-logistic)

7.50 **

$(0.20)$

1.06

$(0.05)$

$-0.79 *$ *

$(0.35)$

$-0.02$

$(0.09)$

0.20

$(0.125)$

0.69

$(0.80)$

0.02

$(0.06)$

$-0.14 * *$

$(0.04)$

1.15

$(0.64)$

0.54

$(0.42)$

$-0.42$

$(0.44)$

$-0.03$

$(0.70)$

11.62 * *

(1.15)

-10.72 **

(1.63)

$-0.01$

$(0.01)$

$-2472.15$

*Tests whether the value is significantly different from one. 
Table 4 Maximum likelihood estimates of re-employment probabilities (standard errors in parentheses)

Females $(N=892)$

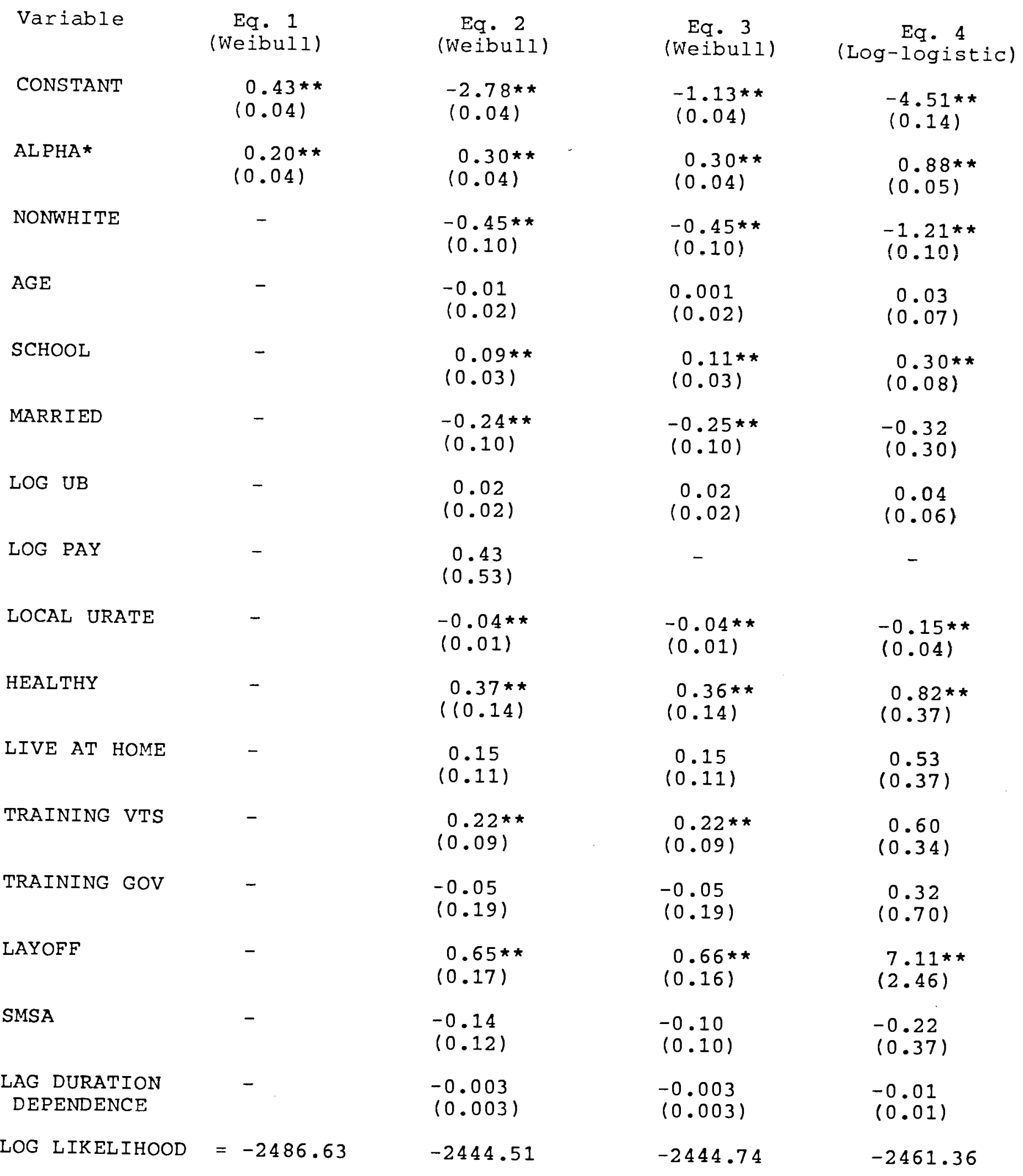

*Tests whether the value is significantly different from one. 
APPENDIX A

Table 5 Maximum likelihood estimates of re-employment probabilities for those with 12 years or less of completed schooling (Weibull model)

$$
\text { Males }(N=678)
$$

Females $(\mathrm{N}=762)$

Variable

CONSTANT

-2.17 *

$(0.04)$

$-3.18 * *$

$(0.05)$

ALPHA

0.35 *

$(0.05)$

0.29 *

$(0.05)$

NONWHITE

$-0.20 * *$

$(0.09)$

$-0.50 * *$

$(0.11)$

AGE

$-0.03$

$(0.02)$

$-0.01$

$(0.02)$

MARRIED

0.08

(0.13)

$-0.20 * *$

$(0.10)$

LOG UB

0.01

$(0.01)$

0.02

$(0.02)$

LOG PAY

0.56

$(0.45)$

0.72

$(0.55)$

LOCAL URATE

$-0.04 * *$

$(0.01)$

-0.04 * *

$(0.01)$

HEALTHY

0.53 * *

$(0.22)$

0.37 **

$(0.15)$

LIVE AT HOME

0.17

$(0.11)$

0.20

$(0.12)$

TRAINING VTS

$-0.05$

(0.10)

$0.30 *$ *

$(0.10)$

TRAINING GOV

$-0.04$

(0.18)

$-0.01$

$(0.20)$

LAYOFF

0.20

$(0.13)$

$0.73 * \star$
$(0.19)$

SMSA

$-0.21 *$

$(0.11)$

$-0.13$

(0.13)

LAG DURATION

DEPENDENCE

$-0.007 * *$

$(0.003)$

$-0.006 * *$

$(0.003)$

LOG LIKELIHOOD =

$-2180.04$

$-2009.39$ 


\section{APPENDIX B}

Table 6

Maximum likelihood estimates of re-employment probabilities for the flow sample (Weibull model)

$$
\text { Males }(N=85)
$$

Females $(N=90)$

Variable

CONSTANT

AL PHA

NONWHITE

AGE

SCHOOL

MARRIED

LOG UB

LOCAL URATE

HEALTHY

LIVE AT HOME

TRAINING VTS

TRAINING GOV

LAYOFF

SMSA

LAG DURATION

DEPENDENCE

LOG LIKELIHOOD =

$$
\begin{aligned}
& -1.34 * * \\
& (0.11)
\end{aligned}
$$$$
0.79 \text { * * }
$$$$
(0.07)
$$

$-0.53 * \star$

$(0.24)$

0.03

$(0.06)$

0.046

$(0.07)$

$-0.49$

$(0.32)$

$-0.06$

$(0.035)$

$-0.05$

$(0.036)$

$-0.63$

$(0.54)$

$-0.05$

$(0.27)$

$-0.02$

$(0.27)$

$-0.41$

$(0.27)$

0.92 * *

$(0.28)$

-0.90 * *

$(0.31)$

0.009

$(0.01)$

$-252.62$
$-2 \cdot 31$ * *

$(0.12)$

0.63 * *

$(0.06)$

$-0.28$

$(0.27)$

$-0.11 *$ *

$(0.055)$

$0.30 *$ *

$(0.11)$

$-0.34$

$(0.27)$

$-0.006$

$(0.06)$

-0.07 *

$(0.04)$

0.14

$(0.49)$

$-0.13$

$(0.33)$

0.44

$(0.285)$

$-1.25$

$(0.735)$

0.65 * *

$(0.32)$

$-0.27$

$(0.30)$

0.008

$(0.008)$

$-257.07$ 
Table 7

Semi-parametric maximum likelihood estimates of re-employment probabilities (Cox's proportional hazard model with Breslow's (1974) modification for tied data)

Males $(\mathrm{N}=85)$

Females $(\mathrm{N}=90)$

\begin{tabular}{|c|c|c|}
\hline NONWHITE & $\begin{array}{l}-0.43 \\
(0.276)\end{array}$ & $\begin{array}{c}-0.18 \\
(0.33)\end{array}$ \\
\hline AGE & $\begin{array}{c}0.02 \\
(0.07)\end{array}$ & $\begin{array}{c}-0.08 \\
(0.07)\end{array}$ \\
\hline SCHOOL & $\begin{array}{c}0.01 \\
(0.08)\end{array}$ & $\begin{array}{l}0.22 * \\
(0.12)\end{array}$ \\
\hline MARRIED & $\begin{array}{l}-0.32 \\
(0.36)\end{array}$ & $\begin{array}{l}-0.196 \\
(0.326)\end{array}$ \\
\hline HEALTHY & $\begin{array}{c}-0.43 \\
(0.55)\end{array}$ & $\begin{array}{c}0.21 \\
(0.49)\end{array}$ \\
\hline TRAINING VTS & $\begin{array}{l}0.03 \\
(0.27)\end{array}$ & $\begin{array}{c}0.32 \\
(0.28)\end{array}$ \\
\hline TRAINING GOV & $\begin{array}{c}-0.425 \\
(0.51)\end{array}$ & $\begin{array}{l}-1.11 \\
(0.74)\end{array}$ \\
\hline LOG UB & $\begin{array}{l}-0.04 \\
(0.04)\end{array}$ & $\begin{array}{l}-0.006 \\
(0.06)\end{array}$ \\
\hline LOCAL URATE & $\begin{array}{l}-0.03 \\
(0.04)\end{array}$ & $\begin{array}{l}-0.05 \\
(0.04)\end{array}$ \\
\hline LIVE AT HOME & $\begin{array}{l}-0.036 \\
(0.29)\end{array}$ & $\begin{array}{l}-0.08 \\
(0.33)\end{array}$ \\
\hline LAYOFF & $\begin{array}{l}0.59 * \star \\
(0.28)\end{array}$ & $\begin{array}{c}0.42 \\
(0.335)\end{array}$ \\
\hline SMSA & $\begin{array}{l}-0.68 * \star \\
(0.31)\end{array}$ & $\begin{array}{l}-0.22 \\
(0.30)\end{array}$ \\
\hline $\begin{array}{l}\text { LAG DURATION } \\
\text { DEPENDENCE }\end{array}$ & $\begin{array}{r}0.008 \\
(0.01)\end{array}$ & $\begin{array}{l}0.008 \\
(0.008)\end{array}$ \\
\hline LOG LIKELIHOOD $=$ & -294.89 & -273.95 \\
\hline
\end{tabular}

